\title{
Protective Effects of Dithiocarbamates against Toxicity of cis-Diamminedichloroplatinum in Mice
}

\author{
Hideaki Shimada, Kentaro TaKahashi, Takayuki Funakoshi and Shoji KoJima* \\ Department of Hygienic Chemistry, Faculty of Pharmaceutical Sciences, Kumamoto University, 5-1 Oe-honmachi, \\ Kumamoto 862, Japan. Received July 17, 1992
}

The protective effects of various dithiocarbamates such as $\mathrm{N}$-benzyl-D-glucamine dithiocarbamate (BGD), $\mathrm{N}$-p-hydroxymethylbenzyl-D-glucamine dithiocarbamate (HBGD), $\mathrm{N}$-p-carboxybenzyl-D-glucamine dithiocarbamate (CBGD), and diethyldithiocarbamate (DDTC) on cis-diamminedichloroplatinum (DDP)-induced toxicity in mice were studied. The mice were injected i.v. with a chelating agent $(1 \mathrm{mmol} / \mathrm{kg})$ immediately or $5 \mathrm{~min}$ after i.v. injection of DDP $(15$ or $20 \mathrm{mg} / \mathrm{kg})$. The lethal toxicity of DDP $(20 \mathrm{mg} / \mathrm{kg})$ was completely prevented by treatment with HBGD or CBGD immediately after DDP. The survival time of mice treated with HBGD or CBGD 5 min after DDP tended to be longer than that treated with BGD or DDTC. Significant increases in blood urea nitrogen (BUN) level and plasma aspartate aminotransferase (AST) activity were observed $3 \mathrm{~d}$ after DDP injection. The increase in BUN level was completely prevented only by HBGD and CBGD among these chelating agents, while increase in AST activity was significantly prevented by treatment with these two agents. Treatment with HBGD or CBGD immediately after DDP $(20 \mathrm{mg} / \mathrm{kg})$ completely protected against DDP-induced diarrhea. These chelating agents significantly decreased the platinum (Pt) contents in the kidney and liver after DDP administration. Treatment with HBGD or CBGD was the most effective in decreasing the renal $\mathrm{Pt}$ content, resulting in maximum protection against DDP-induced renal damage. The antitumor efficacy of DDP $(15 \mathrm{mg} / \mathrm{kg})$ in the colon 26 carcinoma-bearing mice was not affected by HBGD administration.

Keywords cis-diamminedichloroplatinum; renal hepatic toxicity; tissue distribution; dithiocarbamate; chelate effect; colon 26 carcinoma

cis-Diamminedichloroplatinum (DDP) is a highly effective antitumor drug widely used in the therapy of various human tumors, ${ }^{1-5)}$ although renal pathology, ${ }^{1,6}$ the major side effect, and a variety of other side effects ${ }^{7)}$ are frequently observed following its use. Procedures involving sulfur nucleophiles, such as sodium thiosulfate, ${ }^{8)}$ cysteamine, ${ }^{9)} \quad$ 5,2-(3-aminopropylamino)ethylphosphorothioic acid (WR2721), ${ }^{10)}$ 2,3-dimercaptopropanol, ${ }^{11)}$ 2,3-dimercaptosuccinic acid, ${ }^{11)}$ and glutathione ${ }^{12)}$ have been reported to be effective in protecting against DDP-induced nephrotoxicity. The ability of diethyldithiocarbamate (DDTC) to control the nephrotoxicity of DDP was reported by Borch and his collaborators. ${ }^{13-17)}$ Some studies have also indicated that various dithiocarbamate derivatives, such as $N$-methyl-D-glucamine dithiocarbamate, ${ }^{18)} \mathrm{di}$ methyldithiocarbamate, dihydroxyethyldithiocarbamate, sarcosine dithiocarbamate, and iminodiacetic acetate dithiocarbamate, ${ }^{19-21)}$ suppress DDP-induced nephrotoxicity. More recently, we reported that $N$-benzyl-Dglucamine dithiocarbamate (BGD) had a highly protective effect against DDP-induced side effects of renal, gastrointestinal, and bone marrow toxicities without inhibition of its antitumor activity in rats. ${ }^{22,23)}$

The present study was undertaken to further evaluate the protective effects of BGD, $N$ - $p$-hydroxymethylbenzylD-glucamine dithiocarbamate (HBGD), and $N$-p-carboxybenzyl-D-glucamine dithiocarbamate (CBGD), which were synthesized recently by us, as well as DDTC, on DDPinduced toxicity in mice.

\section{Experimental}

Materials DDP was obtained from Sigma Chemical Co. (St. Louis, MO). BGD, HBGD, and CBGD were synthesized by the methods as described in our previous papers. ${ }^{24,25)}$ DDTC was obtained from Wako Pure Chemical Ind. (Osaka). Structures of the dithiocarbamates used are shown in Fig. 1. All other chemicals were of reagent grade.
Survival Experiments Male ddY mice, weighing 25-30g, were purchased from Kyudo Co. (Kumamoto) and housed in metabolic cages with drinking water and diet (CE-2, Clea Japan Inc.) ad libitum. The mice were divided into 8 groups of 6 mice each and injected i.v. with a chelating agent $(1 \mathrm{mmol} / \mathrm{kg})$ immediately or $5 \mathrm{~min}$ after i.v. injection of DDP $(20 \mathrm{mg} / \mathrm{kg})$. Their survival times and body weights were monitored daily for $15 \mathrm{~d}$ after DDP injection. The incidence of diarrhea in mice was measured $3 \mathrm{~d}$ after DDP injection.

Animal Treatments Male ddY mice were injected i.v. with a chelating agent $(1 \mathrm{mmol} / \mathrm{kg})$ immediately or $5 \mathrm{~min}$ after i.v. injection of DDP (15 or $20 \mathrm{mg} / \mathrm{kg}$ ). At $3 \mathrm{~d}$ after DDP injection, they were anesthetized with urethane $(1.5 \mathrm{~g} / \mathrm{kg}$, i.p.), and blood samples were removed from the heart with a syringe to determine blood urea nitrogen (BUN) and aspartate aminotransferase (AST). The kidney and liver were collected for the determination of platinum $(\mathrm{Pt})$ content.

Colon 26 Carcinoma Studies Male CDF1 mice were used to evaluate the effect of HBGD on the antitumor activity of DDP. Colon 26 carcinoma was grown in RPMI 1640 medium supplemented with $10 \%$ fetal calf serum and kanamycin $(100 \mu \mathrm{g} / \mathrm{ml})$. Subcutaneous injection of $0.2 \mathrm{ml}$ $\left(1 \times 10^{6}\right.$ cells) was made at one site in the dorsam. Three days after inoculation, animals were injected i.v. with saline, DDP $(15 \mathrm{mg} / \mathrm{kg})$, or HBGD $(1 \mathrm{mmol} / \mathrm{kg})$. Five min later, the DDP-treated mice injected i.v. with saline or HBGD $(1 \mathrm{mmol} / \mathrm{kg})$. At $10 \mathrm{~d}$ after inoculation, the experiments were terminated.

Analytical Procedures BUN was determined by the diacetylmonoxime

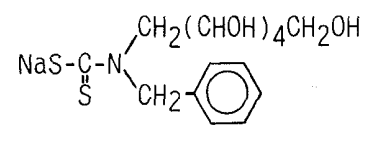

BGD

CBGD

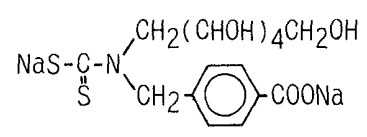

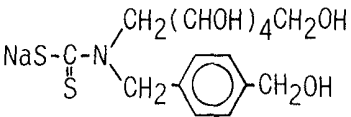

HBGD
Fig. 1. Structures of Dithiocarbamates Used<smiles>CCN(CC)C(=S)S(C)(=O)=S</smiles>

DDTC 
method using a commercial kit, Urea N-Test Wako (Wako Pure Chemical Ind., Osaka). Plasma AST activity was determined using a commercially available kit, S. TA-Test Wako (Wako Pure Chemical Ind., Osaka) Kidney and liver were wet-ashed by the $\mathrm{HClO}_{4}-\mathrm{HNO}_{3}$ method ${ }^{26)}$ and $\mathrm{Pt}$ was determined using a Hitachi Z-8000 atomic absorption instrument equipped with Zeeman background correction and graphite furnace.

Statistical Analysis Data were analyzed by a one-way analysis of Variance. When the analysis indicated that a significant difference existed, the treated groups were compared to the controls by Duncan's new multiple range test. Since there were unequal variances in some of the data, it was necessary to use the nonparametric Kruska-Wallis test followed by the appropriate multiple comparison test.

\section{Results}

Table I shows the effects of chelating agents on the lethal toxicity of DDP $(20 \mathrm{mg} / \mathrm{kg})$ in mice. This toxicity was completely prevented by treatment with HBGD or CBGD immediately after DDP. When injected with BGD or DDTC immediately after DDP, all of the mice were dead within a few minutes (data not shown). The survival time of mice treated with HBGD or CBGD 5 min after DDP tended to be longer than that treated with BGD or DDTC. The growth of mice treated with HBGD or CBGD immediately after DDP changed little compared to the controls, but body weight loss was observed in other groups (data not shown).

BUN level, plasma AST activity and diarrhea in mice treated with the chelating agents immediately or $5 \mathrm{~min}$ after DDP injection $(20 \mathrm{mg} / \mathrm{kg})$ are shown in Table II. Significant increases in BUN level and AST activity were observed $3 \mathrm{~d}$ after DDP injection, and these were completely prevented when HBGD or CBGD was injected

TABLE I. Effects of Chelating Agents on Survival of Mice after DDP Administration

\begin{tabular}{lc}
\hline \multicolumn{1}{c}{ Treatment } & Survival time $(\mathrm{d})^{a)}$ \\
\hline DDP alone & $3.2 \pm 0.4$ \\
DDP + HBGD (0 min) & $15.0 \pm 0.0^{b)}$ \\
DDP + CBGD (0 min) & $15.0 \pm 0.0^{b)}$ \\
DDP+BGD (5 min) & $3.5 \pm 0.5$ \\
DDP+ HBGD (5 min) & $7.5 \pm 5.8$ \\
DDP + CBGD (5 min) & $7.0 \pm 6.2$ \\
DDP+DDTC (5 min) & $2.7 \pm 0.8$ \\
\hline
\end{tabular}

Mice were injected i.v. with saline or a chelating agent $(1 \mathrm{mmol} / \mathrm{kg})$ immediately or $5 \mathrm{~min}$ after i.v. injection of saline or DDP $(20 \mathrm{mg} / \mathrm{kg})$. a) Six mice per group were used. b) Significantly different from DDP alone $(p<0.05)$.

TABLE II. Effects of Chelating Agents on BUN Level, Plasma AST Activity, and Gastrointestinal Toxicity in Mice after DDP Administration ${ }^{a}$

\begin{tabular}{lccc}
\hline \hline \multicolumn{1}{c}{ Treatment } & BUN (mg/d) & AST (IU/l) & $\begin{array}{c}\text { Diarrhea } \\
\text { observed }\end{array}$ \\
\hline Control & $25.4 \pm 4.6$ & $27 \pm 14$ & $0 / 6$ \\
DDP alone & $227.1 \pm 6.9^{b)}$ & $136 \pm 5^{b)}$ & $6 / 6$ \\
DDP + HBGD (0 min) & $23.2 \pm 4.3^{c)}$ & $32 \pm 5^{c)}$ & $0 / 6$ \\
DDP + CBGD (0 min) & $14.8 \pm 1.6^{c)}$ & $22 \pm 5^{c)}$ & $0 / 6$ \\
DDP + BGD (5 min) & $89.1 \pm 10.0^{b, c)}$ & $66 \pm 15^{b, c)}$ & $3 / 6$ \\
DDP + HBGD (5 min) & $28.7 \pm 4.7^{c)}$ & $54 \pm 16^{b, c)}$ & $2 / 6$ \\
DDP + CBGD (5 min) & $39.5 \pm 11.3^{c)}$ & $54 \pm 8^{b, c)}$ & $2 / 6$ \\
DDP + DDTC (5min) & $139.3 \pm 27.3^{b, c)}$ & $60 \pm 10^{b, c)}$ & $4 / 6$ \\
\hline
\end{tabular}

Mice were injected i.v. with saline or a chelating agent $(1 \mathrm{mmol} / \mathrm{kg})$ immediately or $5 \mathrm{~min}$ after i.v. injection of saline or DDP $(20 \mathrm{mg} / \mathrm{kg})$. After $3 \mathrm{~d}$, a blood sample was collected and diarrhea was observed. a) The values represent the mean \pm S.D. for 6 mice. b) Significantly different from control $(p<0.05)$. c) Significantly different from DDP alone $(p<0.05)$ immediately after DDP. Treatment with HBGD or CBGD at $5 \mathrm{~min}$ after DDP significantly prevented the increase in BUN to almost the control level. Treatment with HBGD or CBGD at $5 \mathrm{~min}$ after DDP significantly prevented the increase in AST activity, but failed to return it to the control level. Treatment with BGD or DDTC at $5 \mathrm{~min}$ after DDP, however, failed to demonstrate a significant reduction either in BUN or AST. The treatment with HBGD or CBGD immediately after DDP completely protected against DDP-induced diarrhea, however, this was not satisfactorily prevented in other groups treated with the chelating agents.

The tissue distribution of $\mathrm{Pt}$ in mice at the end of the experiments is shown in Table III. The content of $\mathrm{Pt}$ deposited in the kidney after DDP injection was significantly decreased by all chelating agents used. HBGD and CBGD treatment immediately after DDP maximally reduced the content of $\mathrm{Pt}$ in the kidney. All the chelating agents except DDTC significantly reduced the content of $\mathrm{Pt}$ in the liver.

We further examined the effects of the chelating agent on the toxicity of DDP at a lower dose $(15 \mathrm{mg} / \mathrm{kg})$, which had a less lethal effect in mice (Table IV). BUN level and plasma AST activity significantly increased in mice after DDP injection. Only HBGD and CBGD among these chelating agents significantly prevented the increase in BUN level. The increase in AST activity was significantly prevented by treatment with BGD, HBGD, or CBGD, while DDTC treatment did not prevent the increase either in BUN or AST.

TABle III. Effects of Chelating Agents on Tissue Distribution of Pt in Mice after DDP Administration

\begin{tabular}{lcc}
\hline \multirow{2}{*}{ Treatment } & \multicolumn{2}{c}{ Distribution of Pt $(\mu \mathrm{g} \mathrm{Pt} / \mathrm{g} \text { wet tissue })^{a)}$} \\
\cline { 2 - 3 } & Kidney & Liver \\
\hline DDP alone & $10.21 \pm 2.15$ & $17.48 \pm 2.35$ \\
DDP + HBGD (0 min) & $2.65 \pm 0.69^{b)}$ & $4.17 \pm 0.27^{b)}$ \\
DDP + CBGD (0 min) & $2.19 \pm 0.32^{b)}$ & $3.31 \pm 0.86^{b)}$ \\
DDP + BGD (5 min) & $7.22 \pm 1.29$ & $9.43 \pm 1.32^{b\rangle}$ \\
DDP + HBGD (5 min) & $4.47 \pm 1.12^{b)}$ & $5.25 \pm 0.63^{b)}$ \\
DDP + CBGD (5 min) & $5.99 \pm 0.15^{b)}$ & $7.35 \pm 0.33^{b)}$ \\
DDP + DDTC (5 min) & $7.06 \pm 0.93$ & $13.40 \pm 2.99$ \\
\hline
\end{tabular}

Mice were injected i.v. with saline or a chelating agent $(1 \mathrm{mmol} / \mathrm{kg})$ immediately or $5 \mathrm{~min}$ after i.v. injection of DDP $(20 \mathrm{mg} / \mathrm{kg})$. The mice were killed $3 \mathrm{~d}$ after DDP and the tissue distribution of $\mathrm{Pt}$ was determined by the atomic absorption method. a) The values represent the mean \pm S.D. for three to six mice. b) Significantly different from DDP alone $(p<0.05)$.

Table IV. Effects of Chelating Agents on BUN Level and Plasma AST Activity in Mice after DDP Administration ${ }^{a)}$

\begin{tabular}{lcc}
\hline \multicolumn{1}{c}{ Treatment } & BUN (mg/dl) & AST (IU/l) \\
\hline Control & $25.4 \pm 4.6$ & $27 \pm 14$ \\
DDP alone & $65.3 \pm 11.4^{b)}$ & $102 \pm 42^{b)}$ \\
DDP+BGD (5 min) & $49.2 \pm 7.6^{b)}$ & $31 \pm 10^{c)}$ \\
DDP+HBGD (5 min) & $28.0 \pm 9.0^{c)}$ & $47 \pm 14^{c)}$ \\
DDP+CBGD (5 min) & $25.2 \pm 9.7^{c)}$ & $35 \pm 8^{c)}$ \\
DDP+DDTC (5 min) & $47.6 \pm 9.2^{b)}$ & $57 \pm 17^{b)}$ \\
\hline
\end{tabular}

Mice were injected i.v. with saline or a chelating agent $(1 \mathrm{mmol} / \mathrm{kg}) 5 \mathrm{~min}$ after i.v. injection of saline or DDP $(15 \mathrm{mg} / \mathrm{kg})$. After $3 \mathrm{~d}$, a blood sample was collected. a) The values represent the mean \pm S.D. for five or six mice. $b$ ) Significantly different from control $(p<0.05)$. c) Significantly different from DDP alone $(p<0.05)$. 
TABLE V. Effects of Chelating Agents on Tissue Distribution of Pt in Mice after DDP Administration

\begin{tabular}{llc}
\hline \multicolumn{1}{c}{ Treatment } & \multicolumn{2}{c}{ Distribution of Pt $(\mu \mathrm{g} \mathrm{Pt} / \mathrm{g} \text { wet tissue })^{a)}$} \\
\cline { 2 - 3 } & \multicolumn{1}{c}{ Kidney } & Liver \\
\hline DDP alone & $6.75 \pm 0.93$ & $9.54 \pm 1.44$ \\
DDP + BGD (5 min) & $4.42 \pm 0.49^{b)}$ & $6.81 \pm 0.70^{b)}$ \\
DDP + HBGD (5 min) & $3.26 \pm 0.49^{b)}$ & $3.81 \pm 0.70^{b)}$ \\
DDP + CBGD (5 min) & $3.24 \pm 0.27^{b)}$ & $5.34 \pm 0.54^{b)}$ \\
DDP + DDTC (5 min) & $4.38 \pm 0.88^{b)}$ & $8.70 \pm 0.89$ \\
\hline
\end{tabular}

Mice were injected i.v. with saline or a chelating agent $(1 \mathrm{mmol} / \mathrm{kg}) 5 \mathrm{~min}$ after i.v. injection of DDP $(15 \mathrm{mg} / \mathrm{kg})$. The mice were killed $3 \mathrm{~d}$ after DDP and the tissue distribution of Pt was determined by the atomic absorption method. a) The values represent the mean \pm S.D. for three to six mice. b) Significantly different from DDP alone $(p<0.05)$.

TABLE VI. Effect of HBGD on the Anti-tumor Activity of DDP ${ }^{a}$

\begin{tabular}{lcccc}
\hline Treatment & $\begin{array}{c}\text { Tumor } \\
\text { weight } \\
(\mathrm{mg})\end{array}$ & $\begin{array}{c}\text { BUN } \\
(\mathrm{mg} / \mathrm{dl})\end{array}$ & $\begin{array}{c}\text { AST } \\
(\mathrm{IU} / \mathrm{l})\end{array}$ & $\begin{array}{c}\text { Body } \\
\text { weight gain } \\
(\mathrm{g} / 10 \mathrm{~d})\end{array}$ \\
\hline Control & $210 \pm 22$ & $20.3 \pm 2.9$ & $37 \pm 12$ & $3.4 \pm 0.7$ \\
DDP alone & $4 \pm 5^{b)}$ & $62.7 \pm 8.6^{b)}$ & $92 \pm 34^{b)}$ & $-2.6 \pm 1.0^{b)}$ \\
DDP + HBGD & $13 \pm 12^{b)}$ & $20.8 \pm 4.9^{c)}$ & $39 \pm 6^{c)}$ & $3.3 \pm 0.2^{c)}$ \\
HBGD alone & $155 \pm 30^{b, c)}$ & $21.2 \pm 2.1^{c)}$ & $38 \pm 8^{c)}$ & $4.2 \pm 0.8^{c}$
\end{tabular}

Mice were each given one inoculum of $10^{6}$ viable cells of colon 26 carcinoma in the right region of the dorsum. They were injected i.v. with saline, DDP $(15 \mathrm{mg} / \mathrm{kg})$, or HBGD $(1 \mathrm{mmol} / \mathrm{kg}) 3 \mathrm{~d}$ after inoculation. Five min later the DDP-treated mice were injected i.v. with saline or HBGD $(1 \mathrm{mmol} / \mathrm{kg})$. At $10 \mathrm{~d}$ after inoculation, the experiments were terminated. a) The values represent the mean \pm S.D. for four to six mice. b) Significantly different from control $(p<0.05)$. $c$ ) Significantly different from DDP alone $(p<0.05)$

Table $\mathrm{V}$ shows the effects of the chelating agents on the contents of $\mathrm{Pt}$ in the kidney and liver of mice after DDP injection. In both organs $\mathrm{Pt}$ deposit was significantly decreased by these chelating agents. The reducing effects of HBGD and CBGD on the renal Pt content were greater than those of BGD and DDTC, and HBGD was most effective of the four in removing $\mathrm{Pt}$ from the liver.

The effect of HBGD administration on the antitumor activity of DDP was examined in mice inoculated s.c. with $10^{6}$ tumor cells of colon 26 carcinoma (Table VI). The use of HBGD to prevent the renal and hepatic toxicity of DDP $(15 \mathrm{mg} / \mathrm{kg})$ did not lead to a significant change in the tumor size when compared to animals treated with DDP alone.

\section{Discussion}

The present study was carried out to evaluate the protective effects of BGD, HBGD, CBGD, and DDTC on the toxicity of DDP in mice. When injected with BGD or DDTC immediately after DDP, all of the mice were dead within a few minutes. BGD and DDTC were then injected $5 \mathrm{~min}$ after DDP injection. Their effects on the acute toxicity of DDP injection $(20 \mathrm{mg} / \mathrm{kg})$ were not as great as the protective effects of HBGD and CBGD against DDP toxicity and the treatment with HBGD or CBGD immediately after DDP was more effective than the delayed treatment with these same agents (Table I). This is supported by the finding that treatment with HBGD and CBGD immediately after DDP was the most effective in preventing body weight loss and diarrhea induced by DDP. It has been reported that DDP-induced nephrotoxicity results in increases in $\mathrm{BUN}^{13,27)}$ and serum creatinine. ${ }^{21,28 \text { ) }}$ The present results showed that BUN level increased after injection of DDP (15 or $20 \mathrm{mg} / \mathrm{kg}$ ). This induced increase was completely prevented only by HBGD and CBGD among the chelating agents used. DDP injection also caused an increase in serum AST activity, presumably due to the hepatic damage, and this increase was significantly prevented by treatment with HBGD or CBGD. DDTC was not able to prevent the DDP-induced renal damage when administered $5 \mathrm{~min}$ after DDP. It was reported that when DDTC was administered i.p. to rats and mice immediately after DDP injection, it was not able to prevent the increase in BUN, while when administered between 1 and $4 \mathrm{~h}$ after DDP, it significantly prevented the increase in BUN and loss in body weight. ${ }^{13,17)}$ Borch and Pleasants ${ }^{13)}$ suggested that DDTC administered $30 \mathrm{~min}$ prior to or concurrent with DDP is rapidly metabolized before $\mathrm{Pt}$ accumulates, and that rescue between $45 \mathrm{~min}$ and $4 \mathrm{~h}$ is effective because DDTC concentration in the tubular fluid is adequate for Pt chelation and removal. Thus, these results indicated that treatment with HBGD or CBGD offers the advantage of protecting against the DDPinduced toxicity even though these chelating agents are administered immediately or $5 \mathrm{~min}$ after DDP injection, whereas DDTC provides no satisfactory protection against the toxicity caused by DDP.

The chelating agents used here were effective in removing Pt deposited in the kidney and liver after DDP administration. Treatment with $\mathrm{HBGD}$ or CBGD was the most effective in decreasing renal $\mathrm{Pt}$ content, resulting in maximum protection against the DDP-induced renal damage. We reported that the injection of BGD to rats treated with DDP effectively removed $P t$ from the liver and kidney through biliary and urinary excretion. ${ }^{22)}$ Accordingly, the protective effects of HBGD and CBGD on DDPinduced toxicity are thought to be due to an enhancement of these biliary and urinary excretions of $\mathrm{Pt}$, resulting in lower hepatic and renal Pt contents.

The results obtained reveal clearly that administration of HBGD or CBGD at a level of $1 \mathrm{mmol} / \mathrm{kg} 5 \mathrm{~min}$ after DDP $(15 \mathrm{mg} / \mathrm{kg})$ affords almost complete protection against DDP-induced nephrotoxicity and body weight loss. The protective effect of HBGD against DDP-induced toxicity without alteration of the antitumor response of DDP, as measured against the colon 26 carcinoma, presumably is due to the chelating agent, although preventing the accumulation of $\mathrm{Pt}$ in the liver and kidney, decreasing the level of DDP available to inhibit tumor cell multiplication. Further studies are required to elucidate the mechanism by which HBGD modifies DDP toxicity.

Acknowledgements We thank Dr. M. Nakano and Dr. S. Fukushima of the Department of Pharmacy, Kumamoto University Hospital for their generous supply of colon 26 carcinoma.

\section{References}

1) M. Dentino, F. C. Luft, M. N. Yum, S. D. Williams and L. H. Einhorn, Cancer, 41, 1274 (1978).

2) J. H. Burchenal, Biochemie, 60, 915 (1978)

3) J. H. Burchenal, K. Kalaher, K. Dew and L. Lokys, Cancer Treat. Rep., 63, 1493 (1979).

4) B. Rosenberg, L. Van Camp, J. E. Trosko and V. H. Mansour, Nature (London), 222, 385 (1969).

5) M. K. Wolpert-DeFilippers, Cancer Treat. Rep., 63, 1453 (1979). 
6) I. H. Krakoff, Cancer Treat. Rep., 63, 1523 (1979).

7) D. D. Von Hoff, R. Schilsky, C. M. Reichert, R. L. Reddick, M. Rozencweig, R. C. Young and F. M. Muggie, Cancer Treat. Rep., 63, 1527 (1979)

8) S. B. Howell and R. Taetle, Cancer Treat. Rep., 64, 611 (1980).

9) D. C. Shrieve and J. W. Harris, Int. J. Radiat. Oncol. Biol. Phys., 8, 585 (1982).

I0) J. M. Yuhas and F. Culo, Cancer Treat. Rep., 64, 57 (1980).

11) J. Graziano, B. Jones and P. Pisciotto, Br. J. Pharmacol., 73, 649 (1982).

12) F. Zunino, O. Tofanetti, A. Besati, E. Cavalletti and G. Savi, Tumori, 69, 105 (1983).

13) R. F. Borch and M. E. Pleasants, Proc. Natl. Acad. Sci. U.S.A., 76, 6611 (1979)

14) R. F. Borch, J. C. Katz, P. H. Lieder and M. E. Pleasants, Proc. Natl. Acad. Sci. U.S.A., 77, 5441 (1980).

15) R. F. Borch and J. C. Katz, Proc. Am. Assoc. Cancer Res., 22, 259 (1981).

16) D. L. Bodenner, P. C. Dedon, P. C. Keng and R. F. Borch, Cancer Res., 46, 2745 (1986).
17) D. L. Bodenner, P. C. Dedon, P. C. Keng and J. C. Katz, Cancer Res., 46, 2751 (1986).

18) M. M. Jones, M. A. Basinger, W. D. Craft, J. L. Domingo and J. M. Llobet, Arch. Toxicol., 59, 167 (1986).

19) M. M. Jones, M. A. Basinger, W. M. Mitchell and C. A. Bradley, Cancer Chemother. Pharmacol., 17, 38 (1986).

20) M. A. Basinger, M. M. Jones, S. G. Gilbreath, E. M. Walker, E. P. Fody and M. A. Mayhue, Toxicol. Appl. Pharmacol., 97, 279 (1989).

21) M. M. Jones and M. A. Basinger, J. Appl. Toxicol., 9, 229 (1989).

22) S. Kojima, T. Inoue, M. Kiyozumi and H. Shimada, Chem. Pharm. Bull., 38, 3127 (1990).

23) M. Kiyozumi, T. Inoue, S. Kojima, S. Hidaka and M. Tsuruoka, Toxicology, 67, 41 (1991).

24) S. Kojima, K. Kaminaka, M. Kiyozumi and T. Honda, Toxicol. Appl. Pharmacol., 83, 516 (1986).

25) H. Shimada, M. Kiyozumi, M. Kawagoe, S. Fukudome and S. Kojima, Chem. Pharm. Bull., 38, 757 (1990).

26) S. Kojima and M. Kiyozumi, Yakugaku Zasshi, 94, 695 (1974).

27) R. S. Goldstein and G. H. Mayor, Life Sci., 32, 685 (1983).

28) G. Singh, Toxicology, 58, 71 (1989). 